\section{Autoregressive process of monthly rainfall amounts in Catalonia (NE Spain) and improvements on predictability of length and intensity of drought episodes}

\section{Xavier Lana ${ }^{1}$ (i) | Raüll Rodríguez-Solà1 (i) | M. Dolors Martínez ${ }^{2}$ | M. Carmen Casas-Castillo ${ }^{3}$ (1) Carina Serra ${ }^{1}$ Ricard Kirchner ${ }^{1}$}

${ }^{1}$ Department of Physics, ETSEIB, Universitat Politècnica de

Catalunya-BarcelonaTech, Barcelona, Spain

${ }^{2}$ Department of Physics, ETSAB,

Catalunya-BarcelonaTech, Barcelona, Spain

${ }^{3}$ Department of Physics, ESEIAAT, Universitat Politècnica de Catalunya-BarcelonaTech, Terrassa, Spain

\section{Correspondence}

Xavier Lana, Department of Physics, ETSEIB, Universitat Politècnica de Catalunya BarcelonaTech, Diagonal 647, 08028 Barcelona, Spain.

Email: francisco.javier.lana@upc.edu
Universitat Politècnica de

\begin{abstract}
Advantages offered by a pluviometric network in Catalonia (NE Spain) have permitted a detailed analysis of the two primary results derived from the autoregressive ARIMA process applied to monthly rainfall amounts. The first was the spatial distribution of the necessary number of previous monthly amounts needed to predict the next amount. The second was the spatial distribution of discrepancies between the real recorded amount and those derived from the autoregressive process. The heterogeneous spatial distribution of both parameters of the ARIMA process is in accordance with the complex spatial distribution of the monthly rainfall regime in Catalonia and fractal/multifractal analyses of several monthly rainfall time series. The statistical distribution of monthly discrepancies also permits a prediction of the probable evolution at monthly scale of drought episodes in terms of length and accumulated rainfall deficit. The results of the ARIMA algorithm are characterized by a few cases of rain gauges with remarkable differences (10-$20 \mathrm{~mm} \cdot \mathrm{month}^{-1}$ ) between real and autoregressive amounts, a predominant number of emplacements lowering $10 \mathrm{~mm} \cdot \mathrm{month}^{-1}$ and a not negligible number of cases with discrepancies lower than $5 \mathrm{~mm} \cdot \mathrm{month}^{-1}$. In terms of percentages with respect to average monthly amounts, most of discrepancies do not exceed $15 \%$, and only in a very few cases they are within the $20-40 \%$ range. It is also worth mentioning that the discrepancies between real and predicted drought lengths use to be no longer than 1 month. Results corresponding to monthly series recorded at two Earth Sciences observatories are described with more detail to illustrate the advantages offered by the ARIMA autoregressive process in the prediction of beginning, continuity and end of drought episodes.
\end{abstract}

\section{KE Y W O R D S}

autoregressive process, drought episodes, monthly rainfall amounts, NE Spain

\section{\begin{tabular}{l|l}
1 & INTRODUCTION
\end{tabular}}

several months depending on the threshold level assumed to define the dry spells (Kutiel, 1985; Kutiel and Maheras, 1992; Lana and Burgueño, 1998a, 1998b; Martín-Vide and Gómez, 1999; Anagnostopoulou
Drought episodes in the Mediterranean region are quite usual, and sometimes characterized by long dry spells of 
1 et al., 2003; Lana et al., 2006a; Serra et al., 2006; 2 Vicente-Serrano, 2006; Diodato and Bellocchi, 2008; 3 Nastos and Zerefos, 2009; Martínez et al., 2010; Sergent 4 et al., 2014; Labuhn et al., 2016, among others). In agree5 ment with Alpert et al. (2002), it is worthy of mention at 6 a global Mediterranean scale the paradoxical tendency to 7 increase daily rainfall records and, at the same time, a 8 decrease of monthly and annual amounts. These facts 9 would imply a very irregular time rainfall pattern, con10 tributing to increase some punctual floods and, at the 11 same time, reinforcing length and severity of drought 12 episodes. It is also noticeable a global revision at 13 European scale of drought episodes since the beginning 14 of the 21st century (Hanel et al., 2018) taking as refer15 ence reconstructed droughts over the last 250 years and characterizing rainfall amount patterns, extreme soil moisture deficits and extreme hydrological droughts.

The area analysed in this paper (Catalonia, NE Spain) also has to be considered adversely affected by these episodes. Nevertheless, due to the orography (Figure 1) of the Eastern Pyrenees and other Littoral and Pre-Littoral chains, a uniform Mediterranean climate (Mc Night and Hess, 2000; Barry and Chorley, 2003) is not expected and the spatial distribution of extreme dry spells and drought episodes deduced for several return periods show notable variability. In fact, the thermometric and pluviometric regimes in Catalonia do not depict homogeneous spatial distributions (Casas et al., 2007; Martínez et al., 2007; Burgueño et al., 2014; Lana et al., 2017; Casas-Castillo

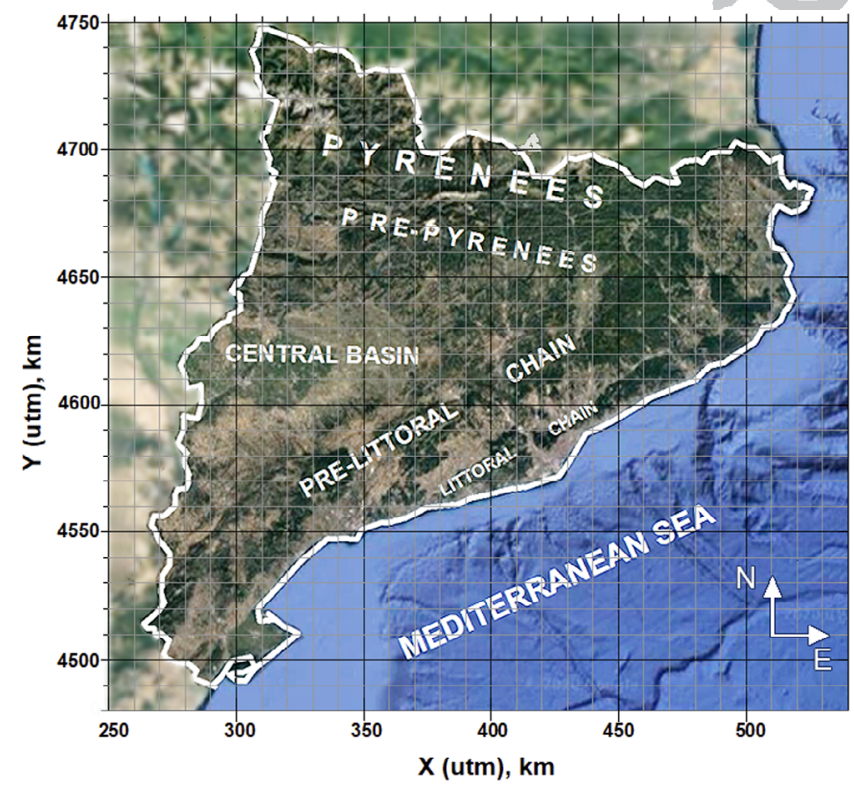

FI G URE 1 Schematic representation of the most relevant orographic elements (Eastern Pyrenees, Central Basin, Littoral and pre-Littoral chain). UTM coordinates grid in $\mathrm{km}$ [Colour figure can be viewed at wileyonlinelibrary.com] et al., 2018; Llabrés-Brustenga et al., 2020). A detailed description of these heterogeneous thermometric and pluviometric regimes can be also found in Clavero et al. (1996).

Bearing in mind that the highest pluviometric records in NE Spain are usually taken in autumn and spring, when these seasons sometimes show monthly rain deficits, it would be convenient to have a computational algorithm to decide if the predicted monthly amounts of the following winter or summer seasons would be sufficient to mitigate the effects generated by the previous drought period. The ARIMA process (Box and Jenkins, 1976) is one of the possible algorithms to forecast monthly rainfall. Besides the appropriate use of this process, a good knowledge of the problems concerning the predictability of monthly amounts would also be necessary. It is expected that the optimum number of previous monthly rainfall amounts for an accurate prediction of the following month depends on specific fractal characteristics of every rainfall record. These characteristics are the degree of randomness or persistence (Hurst exponent), and the number of nonlinear equations and loss of memory of the mathematical process (embedding dimension and Kolmogorov exponent respectively). Additionally, the discrepancies between computed and real monthly amounts could be assumed as depending on the Lyapunov exponents and the Kaplan-Yorke dimension (Lana et al., 2020). All these definitions of fractal parameters and their meanings are explained in detail by Diks (1999).

The degree of difficulty of this autoregressive process can be also quantified by means of mutifractal parameters as the central, maximum and minimum Hölder exponents, spectral multifractal amplitude and spectral asymmetry, all contribute to the complexity index, CI, of the monthly rain amount series. Whereas the first set of cited fractal parameters directly concerns details such as expected number of necessary monthly records and discrepancies between real and computed monthly amounts, the second set of multifractal parameters, deduced from the multifractal detrended fluctuation algorithm (MDFA) (Kantelhardt et al., 2002), leads to a global overview of expected difficulties when applying an autoregressive process.

Whether using one or both algorithms, a heterogeneous spatial distribution of the number of necessary months and the uncertainties of the predictability of the monthly amounts are expected to be in accordance with the spatial heterogeneity of the cited fractal and multifractal parameters. These heterogeneous spatial distributions are to be expected when analysing the monthly rainfall regime in Catalonia. In spite of Catalonia's global standard assignment of Mediterranean climate, a single 
1 pluviometric regime should be discarded due to the com2 plex orography of the region, with the presence of the 3 Pre-Pyrenees, Eastern Pyrenees, another two mountain 4 chains (Littoral and Pre-Littoral chains), a Central Basin, 5 and the variable proximity to the Mediterranean coast 6 (Figure 1).

The contents of this manuscript are developed as follows. Data characteristics and an overview of the complex spatial structure of the rainfall regime in Catalonia are introduced in Section 2. The most relevant characteristics of the dry spells are briefly summarized in Section 3. A brief introduction of the ARIMA auto-regression algorithm is in Section 4. Section 5 summarizes a description of the spatial distribution of the monthly rainfall regime fractal and multifractal parameters which could affect the results of the autoregressive process. A detailed description of the obtained ARIMA results for the pluviometric network is in Section 6. Sections 7 and 8 deal with the statistical distribution of the monthly discrepancies between real and predicted monthly amounts, and give two examples of advantages offered by the ARIMA process analysing the evolution of drought episodes. The discussion of the ARIMA results and suggestions for making more accurate predictions of the end of a drought episode are summarized in Section 9.

\section{DATABASE}

Catalonia (NE Spain) is characterized by a relatively complex orography (Figure 1); there are altitudes exceeding 2,900 $\mathrm{m}$ in some areas of the Eastern Pyrenees, 2,000 m in the Pre-Pyrenees, between 900 and 1,500 $\mathrm{m}$ in the PreLittoral chain, close to $500-600 \mathrm{~m}$ in the Central Basin and only a few hundred meters in the Littoral chain. Due to the great climatic diversity of the region, it is necessary to have an exceptionally dense pluviometric network. Daily rainfall series have been obtained from Servei Meteorològic de Catalunya (SMC, www.meteo.cat), the meteorological agency of Catalonia, including records from two other organizations: Fabra Observatory (Reial Acadèmia de Ciències i Arts, RACA, Barcelona) and Ebre Observatory (Ramon Llull University, URL, and Consejo Superior de Investigaciones Científicas, CSIC, Spanish Government). The daily data were subsequently grouped into monthly totals by the authors of this paper, selecting a set of 96 monthly amount series (Figure 2a); the corresponding emplacements offer a relatively dense spatial network of rain gauges. Additionally, three constraints have been applied to assess the quality of the database. First, several tests of homogeneity and data quality were applied at daily scale by Llabrés-Brustenga et al. (2019) to distinguish the acceptable time series.
Second, for very short data lags of a few days, unknown daily rain amounts have been substituted by those generated by a kriging interpolation process (Stein, 1999; Press et al., 2007) taking into account available daily records close to the gauge without data and the topography of the area around these emplacements. Third, an appropriate length of 40 years has been chosen, which coincides with that used by Lana et al. (2020), who analysed the multifractal properties of the rainfall regime in Catalonia. The results of applying these constraints are illustrated in Figure $2 \mathrm{~b}$, where the chosen 96 rainfall records represent $80-100 \%$ of the available data during the years 1960-2000.

Some spatial patterns showing the complexity of the rainfall regime are presented in Figure 3, where the spatial distribution of the average annual rain amounts is depicted. The differences in the average amounts at annual scale are quite evident when comparing the Central basin $\left(300-500 \mathrm{~mm} \cdot \mathrm{year}^{-1}\right)$, littoral and pre-littoral emplacements (500-800 mm.year ${ }^{-1}$ ) and areas close to the Eastern Pyrenees and the NW of this mountain chain (800-1,000, and $1,100 \mathrm{~mm} \cdot$ year $^{-1}$ in a few places). As a result, the spatial distribution of the parameters of the ARIMA autoregressive process is expected to be heterogeneous.

\section{3 | CHARACTERISTICS OF DROUGHT EPISODES IN CATALONIA}

According to Lana et al. (2006b, 2008b), for return periods of $2,5,10,25$, and 50 years, dry spells with a length varying from 20 to 125 days and a daily rainfall threshold of $0.1 \mathrm{~mm}$ are expected. For a daily rainfall threshold of $10 \mathrm{~mm}$, the spell lengths increase notably, ranging from 40 to 220 days. The heterogeneous spatial distribution of these lengths for $0.1 \mathrm{~mm}$ are characterized by a decreasing South-North gradient (from the Mediterranean coast to the Pyrenees). If the $10 \mathrm{~mm}$ threshold level is considered, the spatial heterogeneity pattern slightly changes to a SW-NE gradient. With respect to extreme drought episodes (Serra et al., 2006), which are characterized by long, and sometimes very long, dry spell lengths, two questions are worthy of mention. First, a high number of rain gauge emplacements with statistically significant positive or negative time trends at annual scale are not detected. Consequently, there is no clear evidence of a global tendency in Catalonia toward more severe and longer drought episodes. Secondly, the number of emplacements with statistically significant positive time trends on extreme spell lengths slightly increases with the threshold levels considered $(0.1,1.0$, 

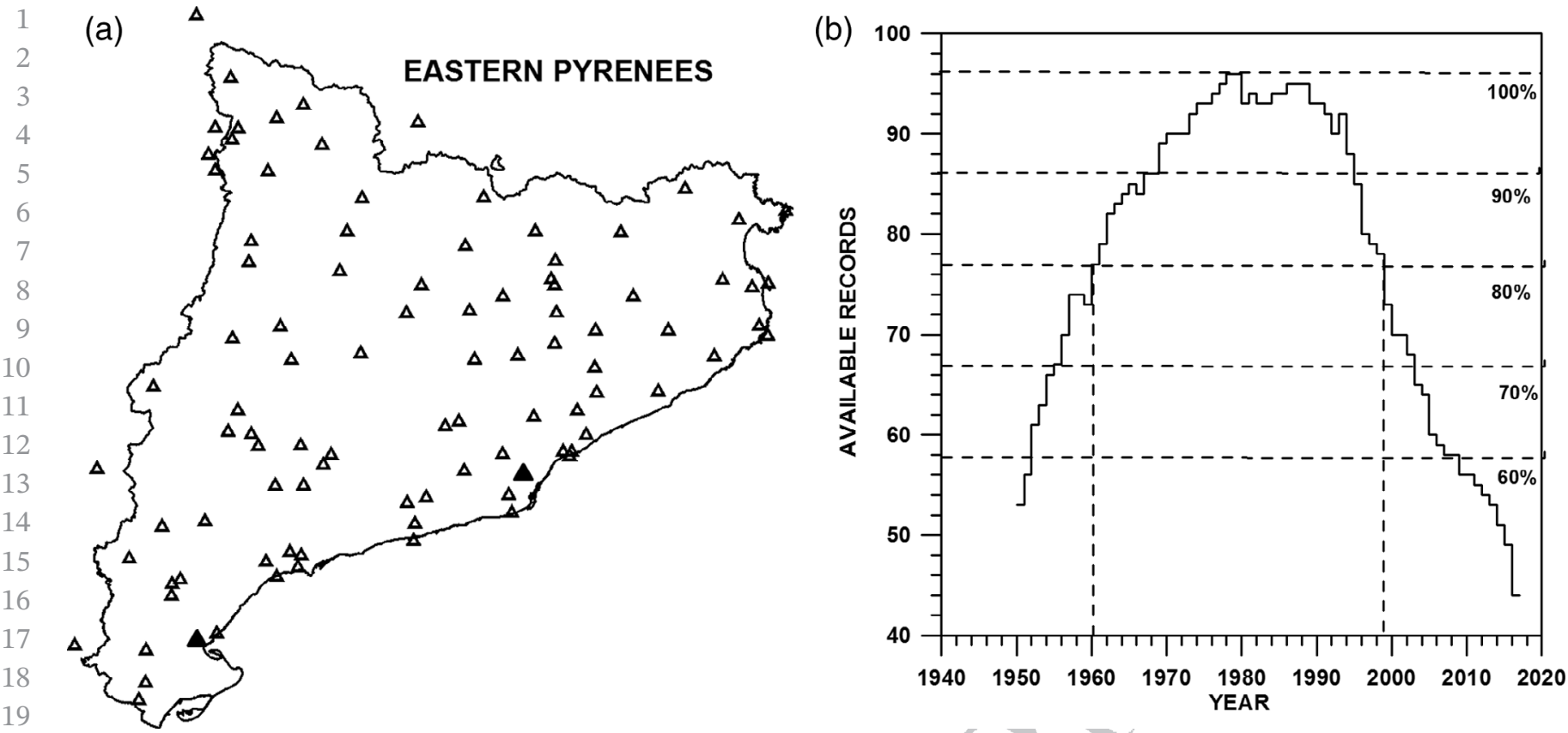

F I G U R E 2 (a) Pluviometric network with the 96 rain gauges. Black triangles depict the emplacement of the Ebre and Fabra Earth Sciences Observatories. (b) Annual evolution on the number of available gauges. Dashed lines indicate the period 1960-2000 finally chosen

AVERAGE ANNUAL AMOUNT (mm)
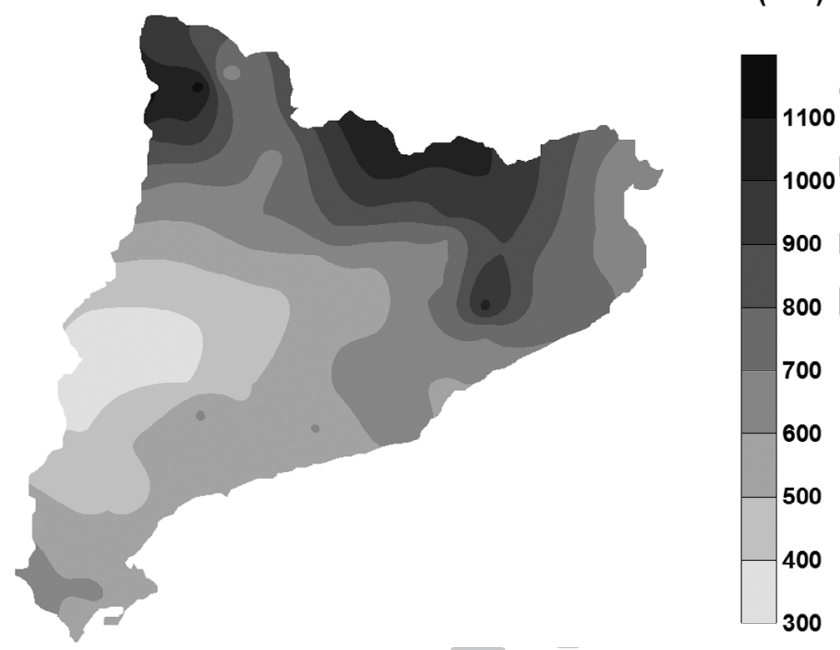

FIG URE 3 Spatial distribution of the average rainfall amounts $\left(\mathrm{mm} \cdot \mathrm{year}^{-1}\right)$ at annual scale

5.0, and $10.0 \mathrm{~mm} \cdot \mathrm{day}^{-1}$ ) and the percentage of emplacements with positive time trends (without taking into account the corresponding statistically significant level) ranges from $64 \%$ ( $0.1 \mathrm{~mm}$ threshold) to $87.5 \%$ (5.0 and $10.0 \mathrm{~mm}$ thresholds).

Some other researches concerning the rainfall regime and drought episodes in Catalonia could be mentioned. Lana et al. (2001) studied the characteristics of rainfall shortage and excess, at monthly scale, in terms of the standardized precipitation index, SPI. Llasat et al. (2009) analysed hydrometeorological extremes (floods and droughts) in NE Spain and a summary of dry spell characteristics in NE Spain were compiled by Lana et al. (2009). More recently, Van Hateren et al. (2019) have investigated hydrological drought forecasts in Catalonia, comparing with meteorological drought episodes analysed from the viewpoint of SPI.

In short, the southern and south-western areas of Catalonia are characterized by the longest dry spells associated with return periods of $2,5,10$, and 25 years and signs of a slight increase in the number of statistically significant positive time trends on dry spells for threshold levels of $0.1,1.0,5.0$, and $10.0 \mathrm{~mm} \cdot$ day $^{-1}$. Drought episodes affecting agriculture, water supply, increment of forest fires and other environmental questions would be caused by notably long dry spells. These episodes of continuous days without rain $\left(0.1 \mathrm{~mm} \cdot \mathrm{day}^{-1}\right.$ threshold $)$ can be very long in some parts of Catalonia. Consequently, at emplacements where dry spells are expected to be long, autoregressive algorithms would be a useful means to predict monthly rainfall and help to determine the length and severity of a potential drought episode.

\section{4 | THE ARIMA} AUTOREGRESSIVE ALGORITHM

The mathematical formulation of the autoregressive integrated moving average $\operatorname{ARIMA}(p, d, 0)$ model (Box and Jenkins, 1976) assumes. 
$\Delta^{d} x(i)=\theta+\mu x(i-1)+\sum_{k=1}^{p} \delta_{k} \Delta^{d} x(i-k)+a_{i} ; i=p+2, \ldots, N$

where $\{x\}$ is a set of $N$ empirical consecutive monthly amounts and $\Delta x$ is the set of first differences $\Delta x(i)=[x$ $(i+1)-x(i)]$, with $\Delta^{d} x(i-k)=[x(i-k+1)-x(i-k)]^{d}$. $\{\theta, \mu, \delta 1, \ldots, \delta p\}$ being the parameters of the autoregressive process of order $p,\left\{a_{i}\right\}$ is a noise series and $d$ is a real number. Alternatively, the $\operatorname{ARIMA}(p, d, 0)$ model, with $d=1.0$, can be written as.

$$
x(i)=\theta+\sum_{k=1}^{p} \delta_{k} x(i-k)+a_{i}, i=p+1, \ldots, N
$$

with the monthly amount series $\{x\}$ used instead of the first differences. Equation (2) is usually designated as autoregressive $\operatorname{AR}(p)$, based on the parameter $p$. The resulting system of linear equations, disregarding the stochastic component $\left\{a_{i}\right\}$, can be represented in matrix form as.

$$
Z=A W
$$

with $Z$ the $\{x(p+1), x(p+2), \ldots, x(N)\}$ vector, $\{x\}$ the number of empiric elements belonging to series, and the $(N-p-1, p+1)$ matrix $A$ multiplying a $p+1$ dimension vector $W$ containing the parameters $\{\theta, \delta 1, \ldots, \delta p\}$ to be solved from Equation (3a). The components of vector $W$ can be estimated by multiplying Equation (3a) by the transposed $A$ matrix, $A^{T}$.

$$
A^{T} Z=A^{T} A W
$$

and bearing in mind that the symmetric matrix $A^{T} A$ can be decomposed in two triangular matrices, it is straightforward to obtain the values of parameters $\{\theta, \delta 1, \ldots, \delta p\}$ taking advantage of Crout's algorithm (Press et al., 1992).

A convincing solution of Equations (1) and (2) has to be based on some criterion to detect the optimum number of monthly amounts to predict the next monthly amount with a certain level of accuracy. The decision can be taken by considering the mean absolute deviation, MAD, parameter (Stephenson et al., 2000; Lana et al., 2016).

$$
\mathrm{MAD}=1.483 \sum_{j=1}^{n}\left|x(j)-x(j)^{*}\right|
$$

$x(j)$ being the real monthly amount and $x(j)^{*}$ the predicted monthly amount, estimated according to Equation (1) or (2), and $n$ the number of predicted monthly amounts. If MAD is less than or equal to one standard deviation of the real monthly amount series, the results of the autoregressive algorithm can be trusted with an acceptable degree of certainty and the predicted monthly amounts would be characterized by low to moderate uncertainty. From a practical point of view, the autoregressive process has to be tested for a high order $p$, even when the MAD parameter has achieved a value lowering the standard deviation of the corresponding monthly series. In this way, minimum possible uncertainty should be obtained. In short, two parameters can be assigned to every monthly amount series: NPMAX, the maximum number of necessary previous months and the corresponding minimum of MAD. If the minimum of MAD for some series exceeds one standard deviation of monthly amounts, the prediction for this series would be discarded or, alternatively, processed again with other algorithms.

\section{5 | A REVISION OF THE FRACTAL STRUCTURE OF THE MONTHLY RAINFALL}

In a previous paper, currently in the editing process (Lana et al., 2020), the fractal structure of the pluviometric regime in Catalonia has been analysed by means of the reconstruction fractal theorem (Diks, 1999) and the multifractal detrended fluctuation analysis, MDFA, (Kantelhardt et al., 2002). This research has permitted a detailed analysis of the physical mechanism complexity of the rainfall regime. Two annexes in this paper include two flow-charts where are schematized the processes concerning the reconstruction fractal theorem, the MDFA algorithm and the influence of the fractal parameters on the ARIMA results.

Concretely, in terms of the reconstruction fractal theorem, the Hurst exponent, $H$, quantifies the randomness or persistence of the monthly rainfall series. The degree of complexity was specified by the embedding dimension, $\mu^{*}$ (required number of nonlinear equations mathematically describing the physical process) and the loss of memory of the physical process was established by the Kolmogorov exponent, $K$ (loss of correlation between consecutive monthly amounts). The uncertainty of the predictability of a monthly amount could be related to the Lyapunov exponents (especially to the first $\lambda_{1}$ Lyapunov exponent) and the Kaplan-Yorke dimension, $D_{K Y}$. The fractal parameters $H, \mu^{*}$ and $K$ are assumed to be closely related to the necessary number of consecutive monthly amounts, in terms of NPMAX, to obtain a confident prediction, by means of an autoregressive process, of the next amount. The discrepancies between real 
1 monthly amounts and those derived from the auto2 regressive process, in terms of $\mathrm{MAD}$, are assumed to be 3 related to the Lyapunov exponents.

4 Another quite different point of view is offered by the 5 MDFA algorithm. In this case, the basic multifractal 6 parameter is the Hölder exponent, $\alpha$, and the multifractal 7 spectrum, mathematically represented by a second order 8 polynomial $f(\alpha)$ of the previously mentioned exponent. 9 Taking advantage of this mathematical formulation, the 10 central, $\alpha_{0}$, Hölder exponent corresponding to a maxi11 mum of $f(\alpha)$, and maximum and minimum, $\alpha_{\max }$ and $12 \alpha_{\mathrm{min}}$, Hölder exponents (extreme exponents 13 accomplishing $f(\alpha)=0$ ) permit the definition of new 14 parameters. Specifically, the spectral amplitude $15 W=\left(\alpha_{\max }-\alpha_{\min }\right)$ and the asymmetry $\gamma=\left(\alpha_{\max }-\alpha_{0}\right) /$ $16\left(\alpha_{0}-\alpha_{\min }\right)$ of the multifractal spectrum can be defined. 17 In agreement with Shimizu et al. (2002), the degree of 18 complexity of the physical process governing the monthly 19 rainfall regime can be summarized by means of the com20 plexity index, CI, which is the addition of the standard21 ized values of the Hölder central exponent, the spectral 22 amplitude and the asymmetry. In this way, CI is not an 23 absolute coefficient of complexity, but permits a quanti24 fied comparison of complexity between the different 25 analysed series. would increase when advancing toward these two last regions. The first Lyapunov exponent would be characterized by two well defined areas of predictive instability, one of them being the Central Basin and Littoral and Pre-Littoral chains; the other covering the rest of Catalohigh instability along the Mediterranean coast. The loss of memory of the physical system, or in other words the decrease of autocorrelation (the Kolmogorov exponent) is characterized by a relatively homogeneous distribution with the exception of the Pre-Littoral chain and the Eastern Pre-Pyrenees and Pyrenees areas. Opposite to these heterogeneous spatial distributions, a high ratio of the monthly regime in Catalonia would be characterized by clear signs of randomness, in terms of the Hurst exponent, except for small emplacements of moderate persistence in Western Catalonia and some small areas of the Eastern Pyrenees, as well as other small areas on the Southern Mediterranean coast and the Central Basin, which are associated with moderate signs of antipersistence. nia, with the exception of a few small emplacements of
The spatial distribution of the different multifractal parameters $\left(\alpha_{0}, \alpha_{\max }, \alpha_{\min }, W\right.$ and $\left.\gamma\right)$ quantifying the degree of difficulty in predicting monthly amounts can be summarized, as mentioned, taking advantage of the complexity index, CI, concept (Shimizu et al., 2002). The predominant pattern is a great domain characterized by values varying from moderately low $(\mathrm{CI}=-0.5)$ to relatively high complexity $(\mathrm{CI}=+1.5)$. Very low complexity $(-0.5$ to -2.5$)$ is also detected in some areas of southwestern Catalonia, a small emplacement on the central Mediterranean coast, as well as in the Pre-Littoral chain and eastern Pre-Pyrenees. It is also worth mentioning the high complexity, reaching $\mathrm{CI}$ intervals ranging from +1.5 to +3.5 , detected in a limited area in the far north-eastern Mediterranean coast.

In short, some affinity has to be expected between the spatial distribution of auto-regression results (NPMAX and MAD parameters) and the distribution found by Lana et al. (2020) of the fractal and multifractal parameters of the monthly rainfall regime. Nevertheless, not only the complex orography of Catalonia should be taken into account, but the diversity of synoptic situations (anticyclones of long persistence, intense Mediterranean eastern advections, North Atlantic and western frontal passages, convective phenomena in summer and Continental and Atlantic cold outbreaks in winter, among others). Whereas some of these situations favour copious rainfall episodes, others contribute to dry spells, which can occasionally become long drought periods.

\section{6 | RESULTS}

Two illustrative examples of results obtained by the ARIMA autoregressive algorithm are shown in Figure 4a,b. These examples correspond to pluviometric data recorded at the two Earth Sciences observatories mentioned before (Fabra Observatory and Ebre Observatory). Despite the fact that both emplacements are in close proximity to the Mediterranean coast, they have different annual averages due to their latitudes, Fabra, $623.8 \mathrm{~mm} \cdot$ year $^{-1}$ and Ebre, $544.8 \mathrm{~mm} \cdot \mathrm{year}^{-1}$. The pluviometric data quality recorded at these two observatories is excellent, days without records are not detected and, consequently, the krigging process has not been necessary for these two series. The results corresponding to the Ebre Observatory are characterized by an average residual between real and predicted amounts of $7 \mathrm{~mm} \cdot \mathrm{month}^{-1}$ and the standard deviation added to the average reaches a value close to $13 \mathrm{~mm} \cdot \mathrm{month}^{-1}$. Very similar values are obtained for the Fabra Observatory (8 and $14 \mathrm{~mm} \cdot \mathrm{month}^{-1}$, respectively). According to the MAD coefficients obtained $\left(8.03\right.$ and $\left.8.85 \mathrm{~mm} \cdot \mathrm{month}^{-1}\right)$ and the standard deviation of the recorded monthly series (50.05 and 

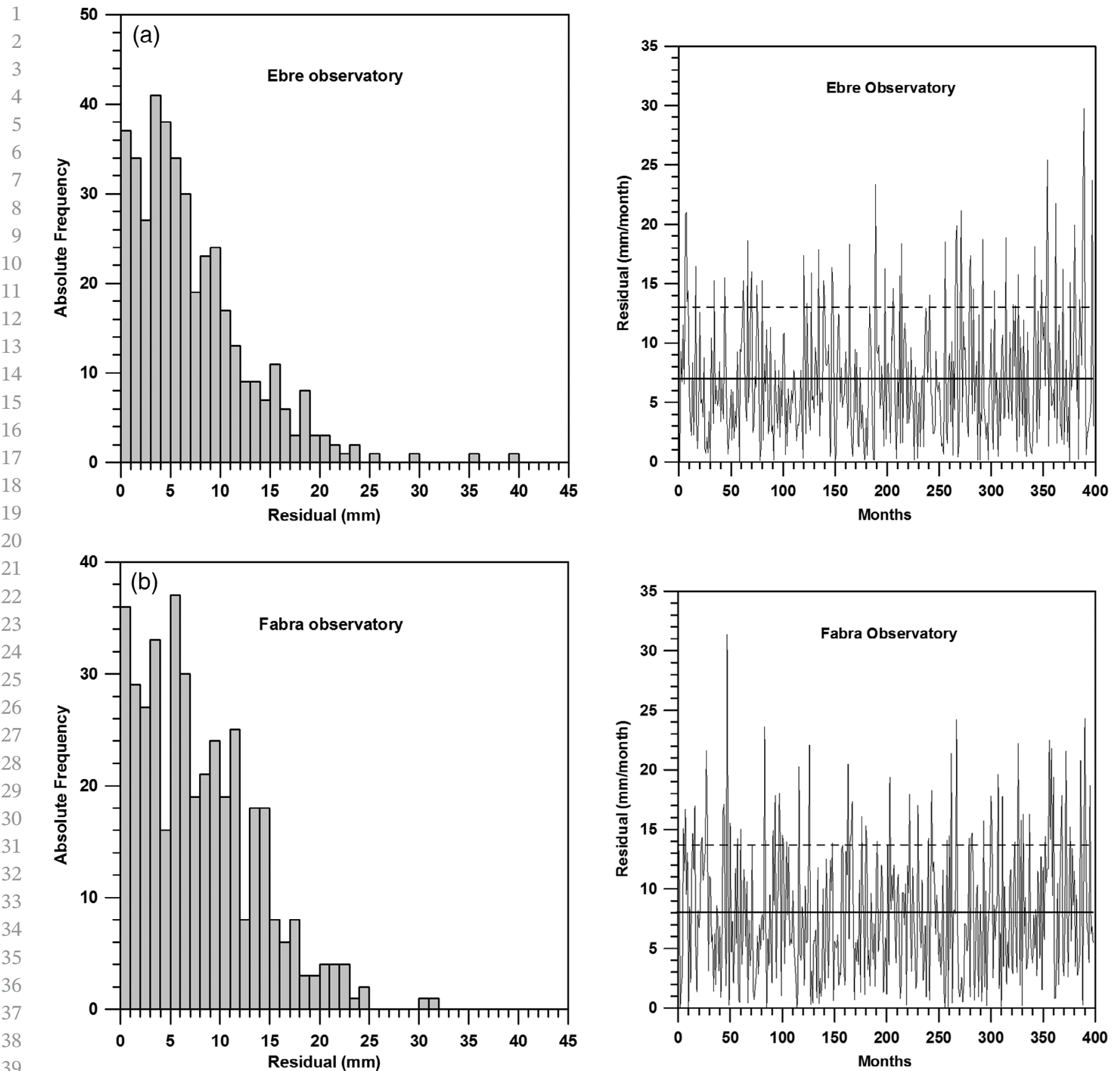

F I G U RE 4 (a) Example of histogram of monthly residuals and evolution of the monthly residuals corresponding to the Ebre Observatory (Southern Mediterranean coast). Continuous and dashed lines are respectively the average and the standard deviation of the residuals added to the average. (b) Example of histogram of monthly residuals and evolution of the monthly residuals corresponding to the Fabra Observatory (Central Mediterranean coast). Continuous and dashed lines are respectively the average and the standard deviation of the residuals added to the average

$49.09 \mathrm{~mm} \cdot \mathrm{month}^{-1}$ ), the ARIMA process could be considered as an appropriate autoregressive algorithm to predict monthly amounts, as it has been established in Section 4, given that MAD values are notably less than the standard deviations of the monthly series. A few monthly discrepancies close to $25-30 \mathrm{~mm} \cdot \mathrm{month}^{-1}$ are also relevant, suggesting some upward time trend of the discrepancies.
Nevertheless it has been verified that this possible trend is not statistically significant. Additionally, two other relevant questions have to be taken into account. First, the number of tested monthly amounts is notably high (close to 400) and from a statistical point of view the results should be convincing. Second, according to histograms of Figure 4a, $\mathrm{b}$, the percentage of discrepancies (59.5 and 56.0\%) is less 
1 than their average. These percentages notably increase (85.4 and 84.4\%) when the standard deviation of discrepancies is added to their average value.

Two examples of the evolution of the differences between real and predicted monthly amounts (quantified by means of MAD) with the increasing number of monthly amounts used, NL, are shown in Figure 5. These two graphics depict a common feature, also detected in most of the 96 auto-regression processes: the detection of a critical point for which the discrepancies notably changes from a quasi linear decrease to a more increasing reduction of their values, finally arriving at a stationary optimum number of months, NPMAX, used in the definitive auto-regression. Different NPMAX and MAD values are expected taking into consideration the relatively complex spatial distribution of the monthly rainfall regime, as suggested by Lana et al. (2020) who analysed the fractal/multifractal structure of the monthly rainfall and revised the maps of average annual amounts and the corresponding standard deviations. The first plot corresponds to an emplacement in the Eastern Pyrenees and it is characterized by a critical point achieved at approximately 260 months. The stationary value of MAD (close to $20 \mathrm{~mm} \cdot \mathrm{month}^{-1}$ ) is achieved by a notably higher number of months (NPMAX close to 350). The second example corresponds to an emplacement on the western face of the Pre-Littoral chain. The critical point is detected close to 170 months and the stationary value of MAD is close to $6 \mathrm{~mm} \cdot \mathrm{month}^{-1}$ after using NPMAX $=240$ consecutive months for the auto-regressive process. These Pre-Littoral chain) differences concerning the critical point and definitive MAD value and necessary number of monthly amounts were expected considering the different rainfall regimes at both emplacements and the annual rainfall amount map of Figure 3.

The spatial distribution and the corresponding histograms of the parameters NPMAX and MAD are described in Figures 6 and 7, respectively. The optimum number, NPMAX, to achieve the best MAD parameter (Figure 6a) is limited to 400 months in 26 cases (the histogram peak for the 380-400 interval). A higher number of monthly amounts could reduce the discrepancies in monthly amounts. Nevertheless, the available monthly amounts to be compared with predicted amounts would be notably reduced and, consequently, the number of samples to obtain a reliable estimation of the parameter MAD would not be sufficient. A first sign of the spatial heterogeneity of the results is the relatively wide range (220400 months) of NPMAX, with approximately a third part of the emplacements characterized by a relatively wide range of 250-300 months. Additionally, the complexity of the auto-regressive process, assumed as a consequence of the complex physical mechanisms of the rainfall regime, is quite evident. Segments of at least 220 months are necessary to obtain an acceptable prediction of the next monthly amount. A detailed description of the spatial heterogeneity is offered by Figure $6 \mathrm{~b}$, where in some domains (Central Basin and Southern Mediterranean coast) it can be observed that the number of required months is the highest. Conversely, the lowest number of

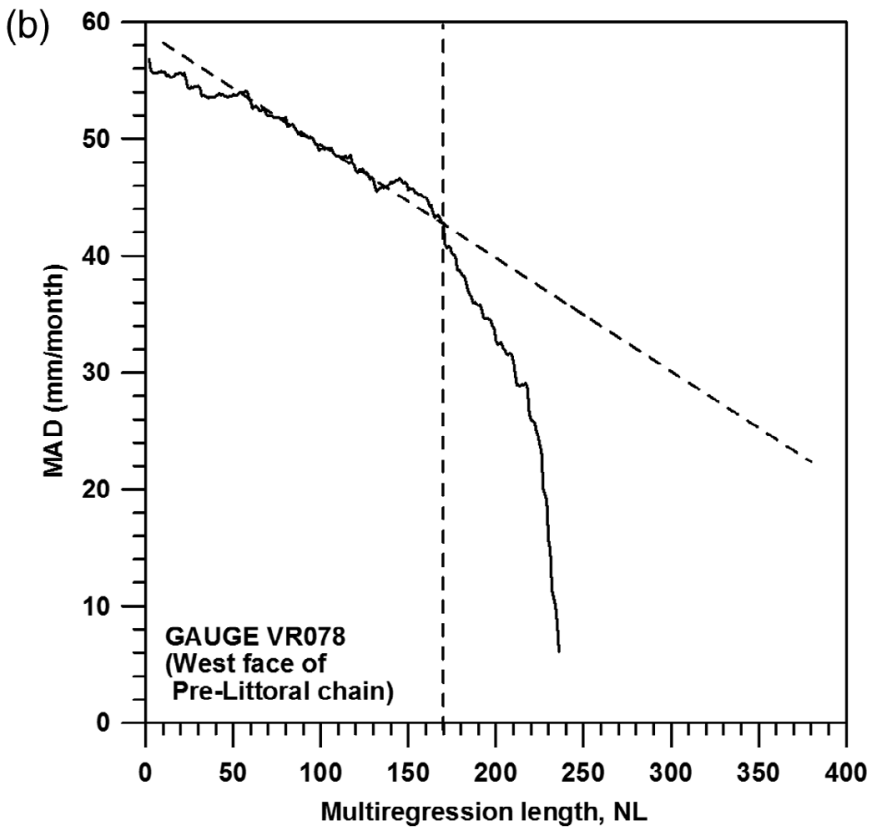

F I G U RE 5 Two examples of autoregressive processes corresponding to gauges AG003 (Eastern Pyrenees) and VR078 (Western face of 

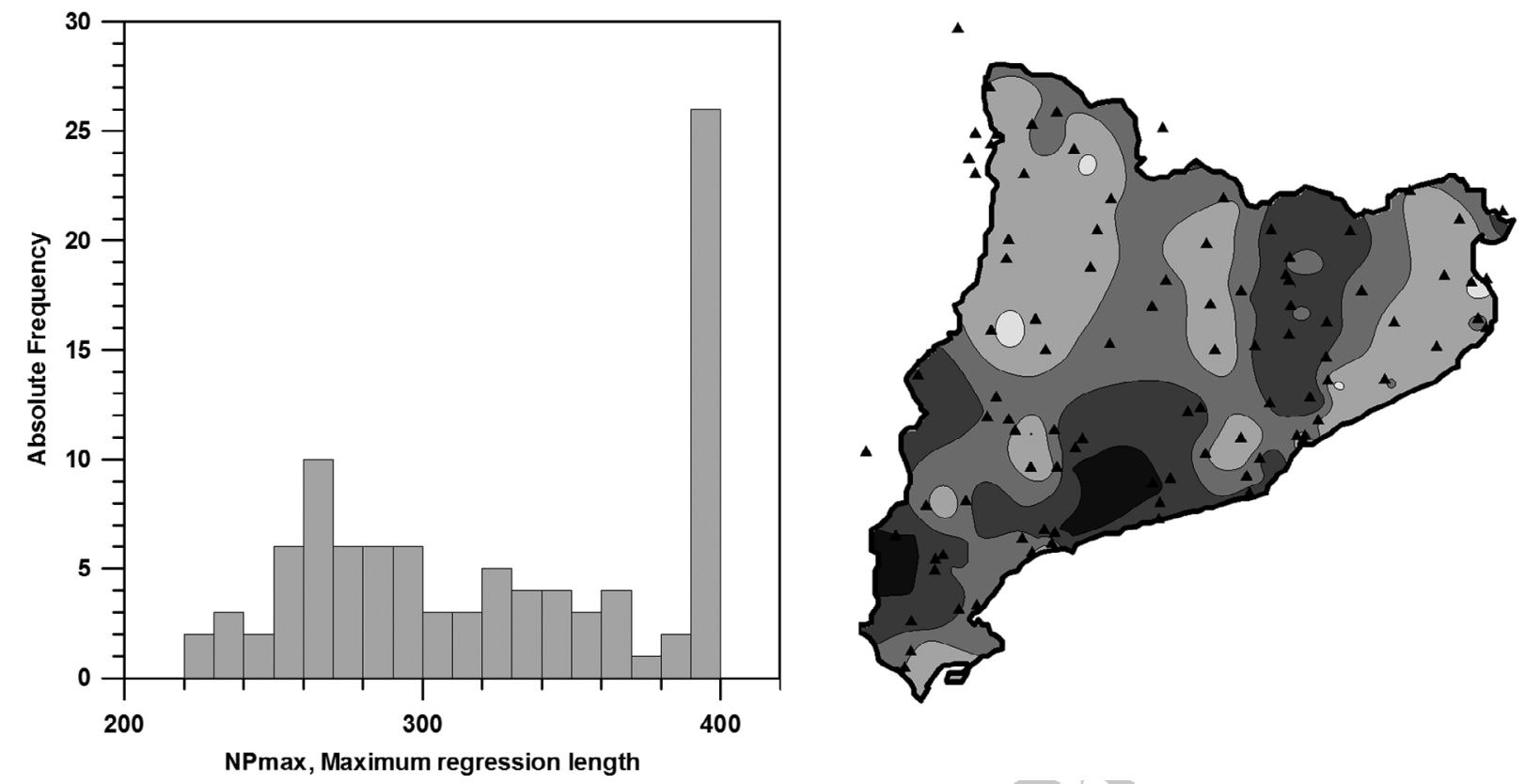

F I G U R E 6 Histogram and spatial distribution of the number of consecutive monthly amounts NPMAX to obtain the best fit between the next monthly real amount and that predicted by the ARIMA algorithm

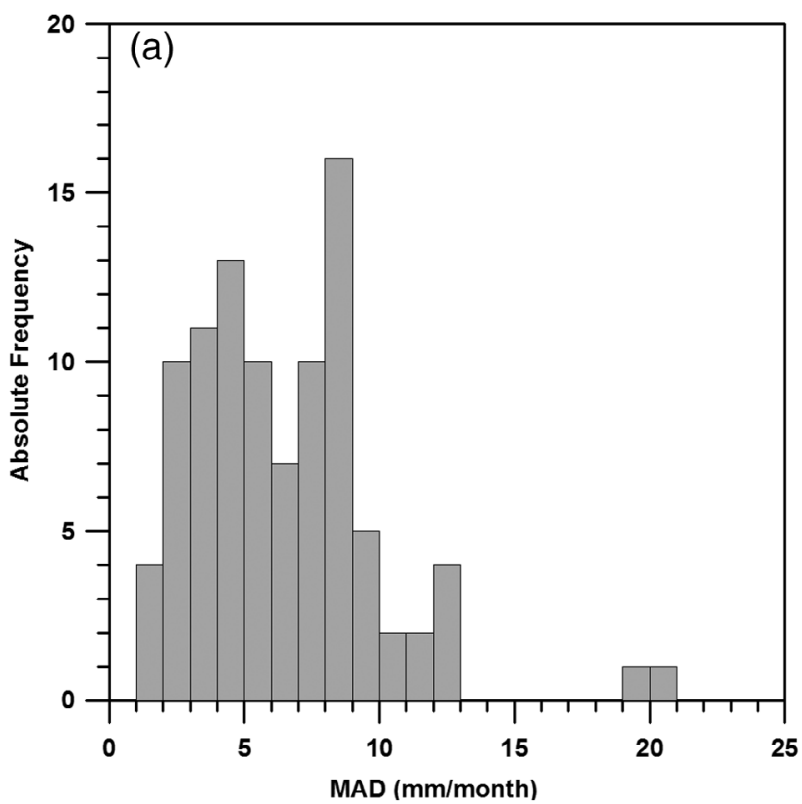

(b)

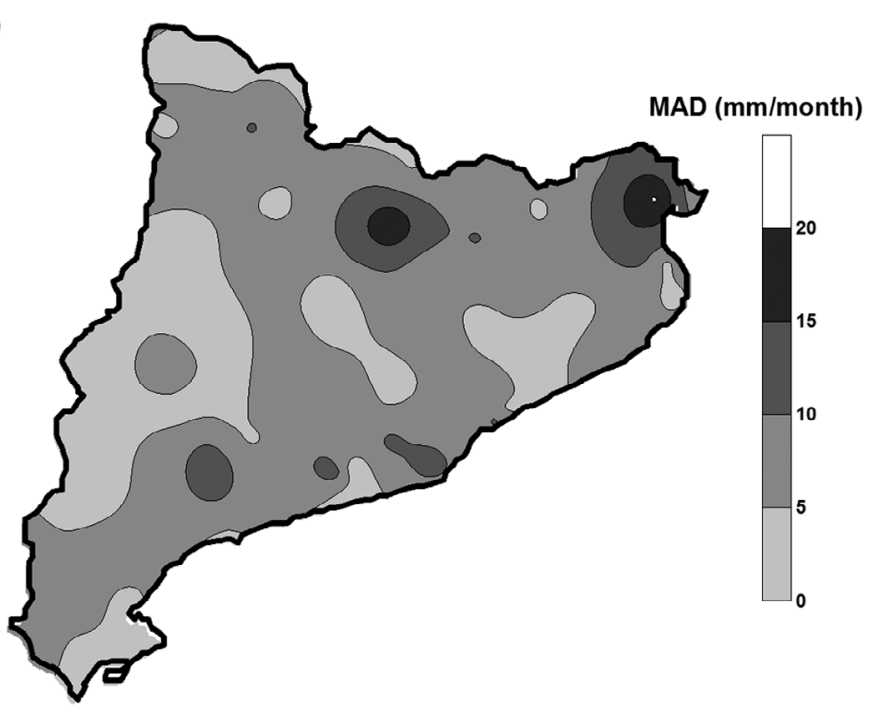

F I G U RE 7 Spatial distribution and histogram of the MAD residual between real and predicted monthly amounts

required months is detected in the North-West and some areas of the Pyrenees and the Northern Mediterranean coast. In spite of these relatively well defined domains, a clear relationship with orographic structures and distance from the Mediterranean coast are not detected.

The results corresponding to MAD parameters are better in comparison to those of NPMAX. By observing the histogram in Figure $7 \mathrm{a}$, the small predominant MAD values are $4-5 \mathrm{~mm} \cdot \mathrm{month}^{-1}$ (13 cases) and
8-9 mm. month ${ }^{-1}$ (16 cases). Additionally, 94 cases correspond to MAD values are equal to or less than $13 \mathrm{~mm} \cdot \mathrm{month}^{-1}$ while only two emplacements are characterized by MAD values within the $19-21 \mathrm{~mm} \cdot \mathrm{month}^{-1}$ range. The main features of the MAD spatial distribution (Figure $7 \mathrm{~b}$ ) are also quite different to those detected using NPMAX. A great part of Catalonia is associated with MAD values not exceeding $10 \mathrm{~mm} \cdot \mathrm{month}^{-1}$, which could be a good threshold to accept a reasonable and 
1 successful application of the autoregressive ARIMA algorithm for the predictability of monthly amounts. Nevertheless, some reduced nuclei are characterized by MAD values within the $10-15 \mathrm{~mm} \cdot \mathrm{month}^{-1}$ interval and only a few cases exceed $15 \mathrm{~mm} \cdot \mathrm{month}^{-1}$, such as those detected in the Pre-Pyrenees domain and the extreme Northern Mediterranean Littoral. In short, a possible dependence of NPMAX and MAD on the orography and the distance from the Mediterranean coast is not clearly observed. In spite of the complexity of the monthly rainfall regime manifested by the high number of previous months to predict the next monthly amount, the MAD values strongly suggest the viability of the ARIMA algorithm to predict forthcoming monthly amounts. However, emplacements with long monthly records would always be necessary due to the range of NPMAX values.

Finally, signs of the MAD parameter's dependence on the average monthly amount, AM, are illustrated in Figure 8, where, according to a nonstatistically significant time trend, the MAD logarithm tends to diminish when $\mathrm{AM}$ increases. In consequence, if only the effect of discrepancies between recorded and predicted monthly amounts quantified by MAD is considered, prediction of monthly amounts would be a bit more reliable for some areas with more copious rainfall regime. Nevertheless, bearing in mind the spatial distribution of average annual amounts (Figure 3), the spatial distribution of MAD (Figure 7), and the low statistical significance of the trend affecting MAD, it has to be assumed that $\mathrm{AM}$ is not a decisive factor, but only another contribution to characterize the auto-regressive process of the monthly rainfall amount.

\section{7 | STATISTICAL DISTRIBUTION OF DISCREPANCIES}

The results obtained from this study suggest that although the discrepancies between real and predicted monthly amounts are not always small, every MAD parameter is lesser than the standard deviation of the corresponding recorded monthly amounts, which favours the use of the ARIMA predictions. The Lmoments formulation (Hosking and Wallis, 1997) has been used for every one of the 96 rain gauges in order to detect the mathematical probability models of the discrepancy between real and predicted amounts. The primary focus is on the cumulative probability functions corresponding to the series of the Fabra and Ebre observatories, which will be used in the next section as examples to analyse the applicability of the ARIMA process to estimate length and strength of some drought episodes.

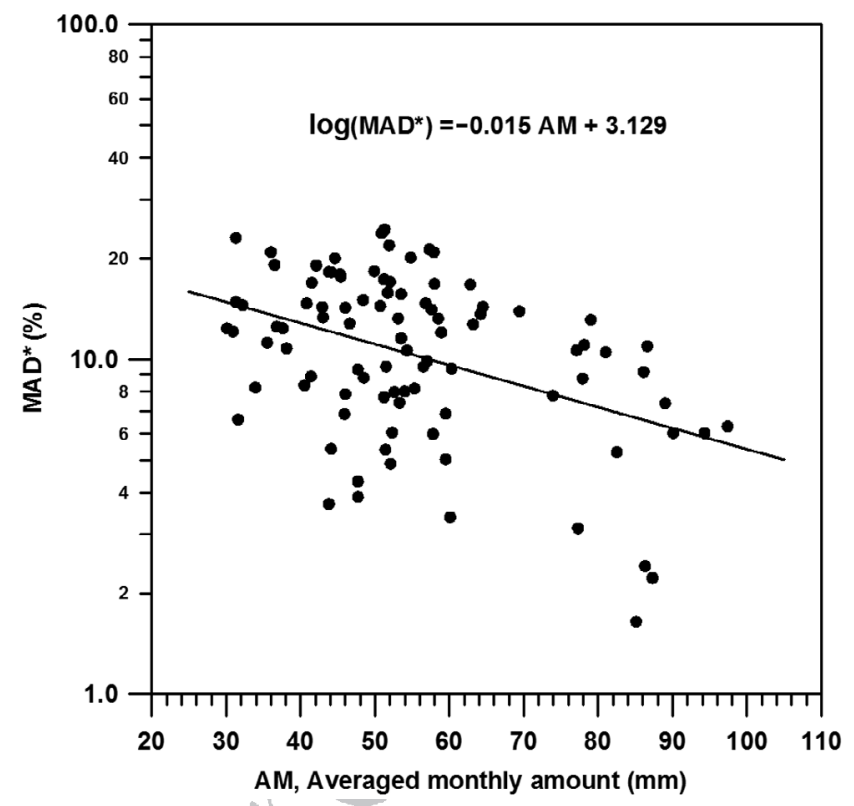

F I G U R E 8 Relationship between the MAD parameter and the average monthly amount for the 96 rainfall series

The 96 pairs of L-Skewness and L-Kurtosis parameters for the different statistical models are represented, together with several L-Skewness-Kurtosis curves for different models of probability functions, in Figure 9a,b. The different models include the Logistic and Generalized Logistic (L and GL), Normal and Log-Normal (N and LN), Gumbel (GU), Weibull (WEI), Pearson Type-3 (PE3) and Generalized Extreme Value (GEV) distributions. Whereas the examples of the Ebre and Fabra observatories are very close to a normal distribution according to the L-Skewness-Kurtosis coordinates and the Kolmogorov-Smirnov test (Dodge, 2008), which guarantees close to $99 \%$ certainty with respect to this distribution function, the whole set of monthly record discrepancies, in spite of the relatively narrow range of LSkewness and L-Kurtosis, could be modelled by a more complete variety of statistical models. Figure 9c depicts two examples of the empiric cumulative probability of discrepancies for the Ebre and Fabra Observatories. These monthly scale discrepancy data would be necessary for predicting length and strength uncertainties of drought episodes for every rain gauge emplacement.

\section{8 | TWO EXAMPLES OF DROUGHT EPISODE PREDICTION}

Drought episodes consisting of a set of consecutive months with rainfall amounts lower than a monthly threshold level and based on consecutive daily amounts (dry spells) lower than a certain daily threshold, as for 

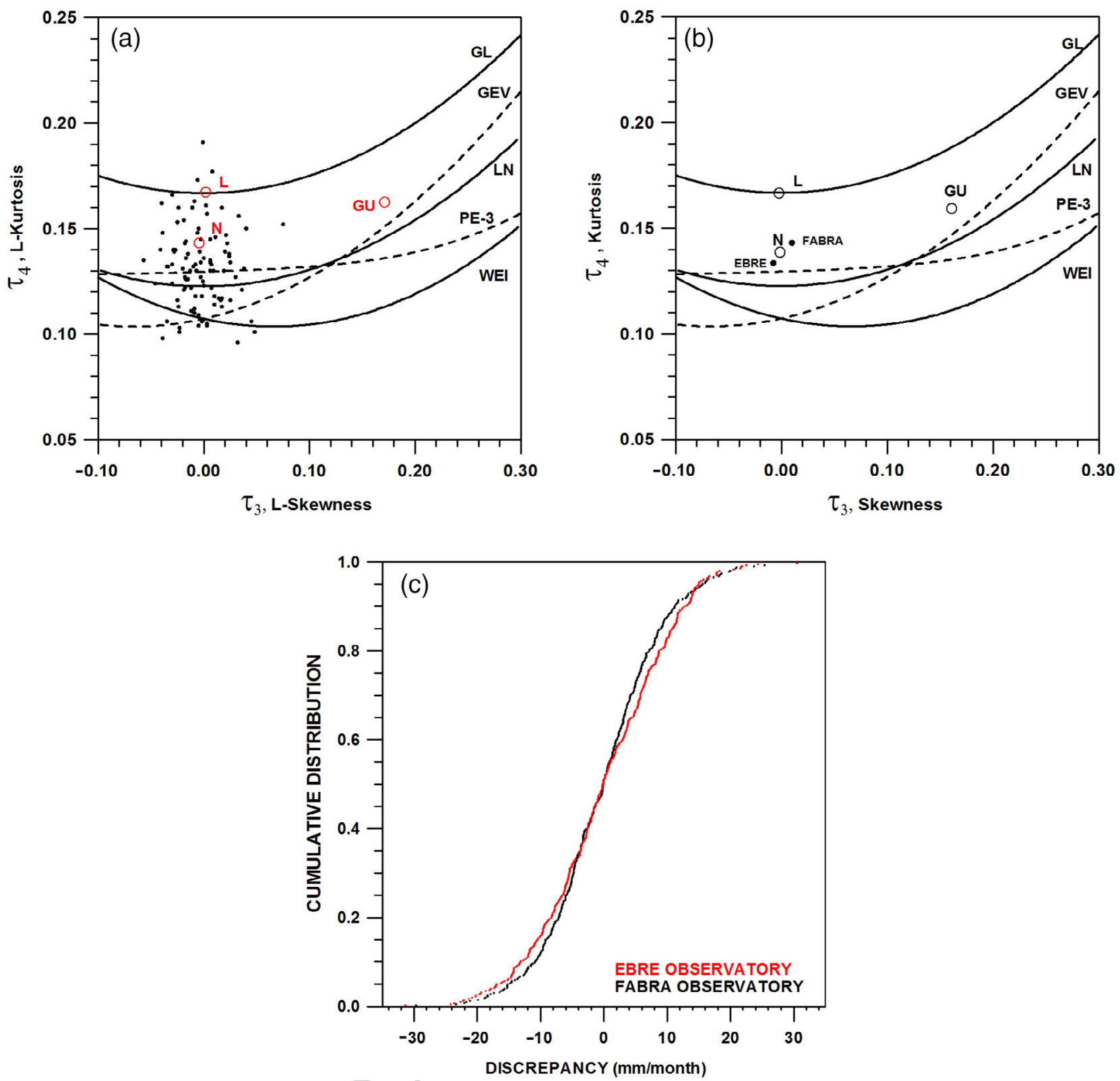

F I G U R E 9 L-skewness-kurtosis diagram for several statistical models and the corresponding empiric values for the discrepancies between predicted and real amounts for (a) the whole set of 96 monthly series and (b) the Ebre and Fabra observatories. (c) Cumulative probability for discrepancies between recorded and predicted monthly amounts corresponding to the Ebre and Fabra datasets [Colour figure can be viewed at wileyonlinelibrary.com]

example $0.1,1.0,5.0$ or $10.0 \mathrm{~mm} \cdot$ day $^{-1}$, could affect agriculture, water supplies and increase the danger of forest fires, among other things. Drought based on the first two levels of dry spells could cause a significant problem. A level of $0.1 \mathrm{~mm} \cdot \mathrm{day}^{-1}$ could imply a drought of at least 1 month without appreciable rain. A level of $1.0 \mathrm{~mm} \cdot$ day $^{-1}$ (equivalent to $30.0 \mathrm{~mm} \cdot \mathrm{month}^{-1}$ ), chosen for the examples introduced here, would imply scarce monthly rainfall. It is evident that a robust prediction strategy would be useful, one that could accurately estimate the forthcoming monthly amounts and predict the length (months) and strength (monthly deficits) of a drought episode. The results for the examples (April 1983 to May 1985) recorded at the Ebre and Fabra observatories are summarized in Table 1 . Monthly amounts lower than $30.0 \mathrm{~mm} \cdot \mathrm{month}^{-1}$ and contributing to a moderate drought episode have been selected assuming the mentioned threshold level of $1.0 \mathrm{~mm} \cdot \mathrm{day}^{-1}$.

For the Ebre Observatory the chosen period of 1983-1985 is characterized by consecutive drought episodes of lengths 2, 1, 2, 3, 1, and 5 months (Table 1, bold types) interspersed by a number of months which had 
1 T A B LE 1 Recorded and predicted monthly amounts at the Ebre and Fabra Observatories for the period 1983-1985

\begin{tabular}{|c|c|c|c|c|}
\hline \multirow[b]{2}{*}{ Month } & \multicolumn{2}{|l|}{ Ebre } & \multicolumn{2}{|l|}{ Fabra } \\
\hline & Amount & Arima & Amount & Arima \\
\hline 1983, 4 & 19.6 & 19.5 & 3.4 & 16.6 \\
\hline 5 & 2.4 & 11.7 & 27.7 & 27.7 \\
\hline 6 & 61.5 & 54.8 & 37.5 & 35.6 \\
\hline 7 & 3.1 & -8.5 & 0.6 & -2.2 \\
\hline 8 & 123.7 & 130.2 & 63.4 & 48.3 \\
\hline 9 & 0.1 & 20.9 & 17.5 & 29.0 \\
\hline 10 & 2.1 & 23.1 & 86.7 & 103.4 \\
\hline 11 & 206.6 & 193.1 & 330.4 & 320.9 \\
\hline 12 & 15.3 & 29.7 & 16.2 & 29.3 \\
\hline 1984,1 & 0.0 & -6.0 & 15.5 & 15.5 \\
\hline 2 & 29.8 & 33.4 & 40.9 & 32.4 \\
\hline 3 & 43.2 & 45.4 & 161.0 & 158.9 \\
\hline 4 & 7.4 & 15.8 & 19.5 & 7.8 \\
\hline 5 & 120.5 & 118.3 & 146.9 & 132.2 \\
\hline 6 & 53.6 & 46.9 & 35.3 & 46.9 \\
\hline 7 & 0.5 & -15.9 & 1.7 & -15.3 \\
\hline 8 & 12.9 & 9.3 & 83.1 & 78.3 \\
\hline 9 & 18.6 & 19.7 & 46.3 & 47.6 \\
\hline 10 & 12.4 & 16.0 & 10.6 & 18.8 \\
\hline 11 & 114.3 & 101.7 & 95.5 & 102.2 \\
\hline 12 & 15.4 & 10.5 & 13.4 & 5.1 \\
\hline 1985,1 & 20.6 & 25.9 & 17.7 & 31.4 \\
\hline 2 & 26.5 & 22.7 & 15.9 & 30.3 \\
\hline 3 & 17.2 & 8.4 & 17.5 & 28.2 \\
\hline 4 & 25.5 & 24.3 & 55.0 & 43.3 \\
\hline 5 & 66.4 & 67.1 & & \\
\hline
\end{tabular}

Note: Bold types indicate monthly amounts less than $30 \mathrm{~mm} \cdot \mathrm{month}^{-1}$, which is assumed as a monthly threshold by considering an average daily threshold of $1.0 \mathrm{~mm} \cdot \mathrm{day}^{-1}$, contributing to drought episodes of several month lengths.

moderate or copious rainfall. June 1983, March and June 1984, and May 1985 had moderate amounts above $30 \mathrm{~mm} \cdot \mathrm{month}^{-1}$, whereas August and November 1983 and May and November 1984 had more copious amounts ranging from 114 to $220 \mathrm{~mm} \cdot \mathrm{month}^{-1}$. In short, $428.6 \mathrm{~mm}$ (79\% of the average annual amount) was recorded in 1984, although $394.9 \mathrm{~mm}$ would have been predicted, an $8 \%$ discrepancy with respect to the real amount recorded. It is worth mentioning that the sequence of dry and wet months (defined by the threshold of $30.0 \mathrm{~mm} \cdot \mathrm{month}^{-1}$ ) contributing to drought lengths does not change when comparing real and predicted amounts, except for February 1984, when a real amount very close to $30.0 \mathrm{~mm} \cdot \mathrm{month}^{-1}$ (assumed monthly drought) changes to a value slightly exceeding the $30 \mathrm{~mm} \cdot \mathrm{month}^{-1}$ threshold according to the ARIMA result. Additionally, taking into account the results summarized in Figure 9c and the range of discrepancies at monthly scale for 1984 (from -16.5 to $8.4 \mathrm{~mm} \cdot \mathrm{month}^{-1}$ ), the probability of exceeding this range of discrepancies is close to $20 \%$. It is also relevant that the example of the long drought episode, from December 1984 to April 1985 is notably well reproduced by the ARIMA results. It is characterized by a very small amount over 5 months $(105.2 \mathrm{~mm})$ with maximum discrepancies of $8.8 \mathrm{~mm} \cdot \mathrm{month}^{-1}$ at the beginning of the episode (December 1984) and a discrepancy of $4.9 \mathrm{~mm} \cdot \mathrm{month}^{-1}$, at the end of this episode (May 1985), when the discrepancy between real and predicted amounts is only $0.7 \mathrm{~mm} \cdot \mathrm{month}^{-1}$

The results corresponding to the Fabra Observatory are in some way quite similar to those obtained from the Ebre Observatory. Nevertheless, some discrepancies must be mentioned. At the Fabra Observatory, the length of the consecutive drought episodes are $2,1,2,1,1$, and 4 , only the last one being exceptionally relevant due to its length (4 months) and the very low amount recorded, $64.5 \mathrm{~mm}$. The lengths of the different drought episodes are delimited by moderate amounts exceeding $30 \mathrm{~mm} \cdot \mathrm{month}^{-1}$ recorded in June, August and October of 1983, February, June, August and September of 1984, and April of 1985. The most copious records are those corresponding to November 1983 and March, May and November of 1984, with amounts varying from 95.5 to $330.4 \mathrm{~mm} \cdot \mathrm{month}^{-1}$. The annual discrepancy between real and predicted amounts in 1984 is $39.3 \mathrm{~mm} \cdot \mathrm{year}^{-1}$ (approximately 6\%), the recorded amount $\left(669.7 \mathrm{~mm} \cdot\right.$ year $\left.^{-1}\right)$ being quite similar to the average annual amount $\left(623.0 \mathrm{~mm} \cdot\right.$ year $\left.^{-1}\right)$. The range of monthly uncertainties in $1984\left(-17.0\right.$ to $\left.11.6 \mathrm{~mm} \cdot \mathrm{month}^{-1}\right)$ suggests that the probability of exceeding this interval is approximately $18 \%$. The sequence of dry and wet months contributing to drought lengths does not change when comparing real and predicted amounts, except for January and February of 1985, when predicted values slightly exceed $30 \mathrm{~mm} \cdot \mathrm{month}^{-1}$ and would shorten the length of the real drought episode from 4 to 2 months. The accumulated real rainfall, $64.5 \mathrm{~mm} \cdot \mathrm{month}^{-1}$, would be exceeded by the predicted, $85.0 \mathrm{~mm} \cdot \mathrm{month}^{-1}$. In spite of this shortcoming of the predictive process, the end of the drought episode is well detected in April, when the predicted amount notably exceeds the $30 \mathrm{~mm} \cdot \mathrm{month}^{-1}$ level and is only $11.7 \mathrm{~mm} \cdot \mathrm{month}^{-1}$ less than the real amount. An erroneous prediction of the drought end (predicted amount equal to $30.0 \mathrm{~mm} \cdot \mathrm{month}^{-1}$ ) would imply a discrepancy equalling to or exceeding 
$25.5 \mathrm{~mm} \cdot \mathrm{month}^{-1}$, equivalent to a probability close to $0.5 \%$.

In addition to these detailed results corresponding to the Ebre and Fabra Observatories, the spatial distribution of the average monthly discrepancies, quantified as percentages with respect to the real amounts, is illustrated in

Fio Figure 10 for the 96 time series. A great part of the domain covered by the pluviometric network is

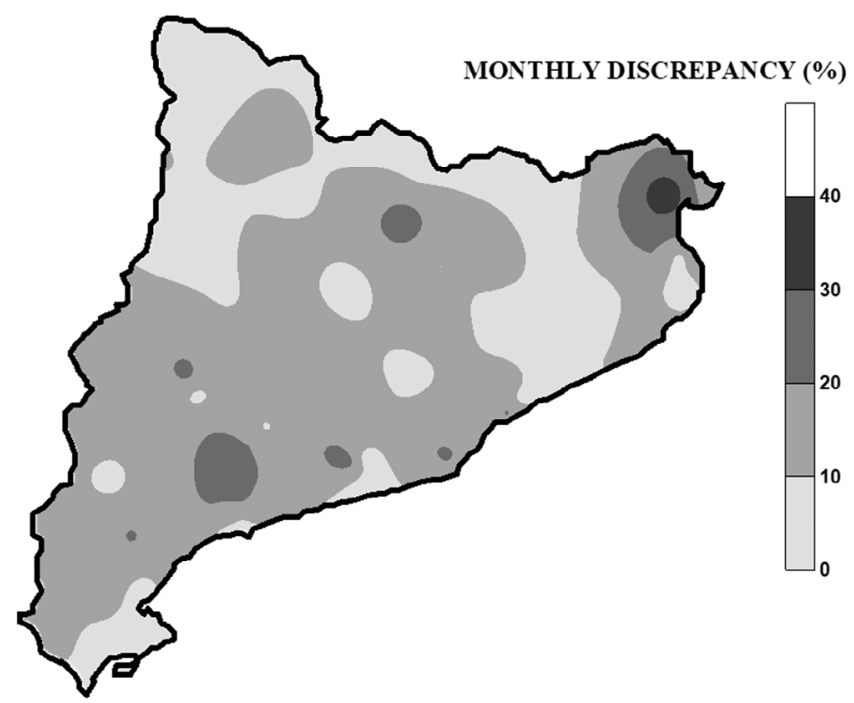

F I G URE 10 Spatial distribution of the average monthly discrepancy, in percentage, with respect to the recorded amounts, based on the 96 monthly amounts series and the corresponding predicted amounts

characterized by averaged percentages of positive or negative discrepancies between $0-10 \%$ and $10-20 \%$ of the real monthly amounts (as in the cases of the Ebre and Fabra Observatories) and only small areas are associated with percentages within the $30-40 \%$ range. In terms of the chosen threshold level of $30.0 \mathrm{~mm} \cdot \mathrm{month}^{-1}$ to define drought episodes, the expected errors concerning the predicted months, leading to an incorrect transition from a dry(wet) to a wet(dry) month would be notably modest and not exceed $6 \mathrm{~mm} \cdot \mathrm{month}^{-1}$. For example, the predicted monthly amount at the Ebre observatory in February 1984 (Table 1) differs by only $3.6 \mathrm{~mm}$. This predicted monthly amount should not be assumed to contribute to the continuity of a drought episode. Nevertheless, this small difference with respect to $30 \mathrm{~mm} \cdot \mathrm{month}^{-1}$ should be carefully taken into consideration and the possibility of an extended drought not absolutely discarded. A quite different case would be that detected for January and February 1985 at the Fabra observatory. The predicted amounts for these 2 months exceed the real records by 13.7 and $14.4 \mathrm{~mm} \cdot \mathrm{month}^{-1}$ (Table 1); the drought episode is then notably shortened in comparison with the real situation. In this case, the predicted monthly amounts would be a bit more convincing, leading to the wrong assumption of an interruption in the drought episode.

As a complement to the advantages offered by the ARIMA algorithm predicting monthly amounts and detecting initial and final months of drought episodes, Figure 11a illustrates the evolution of the real and

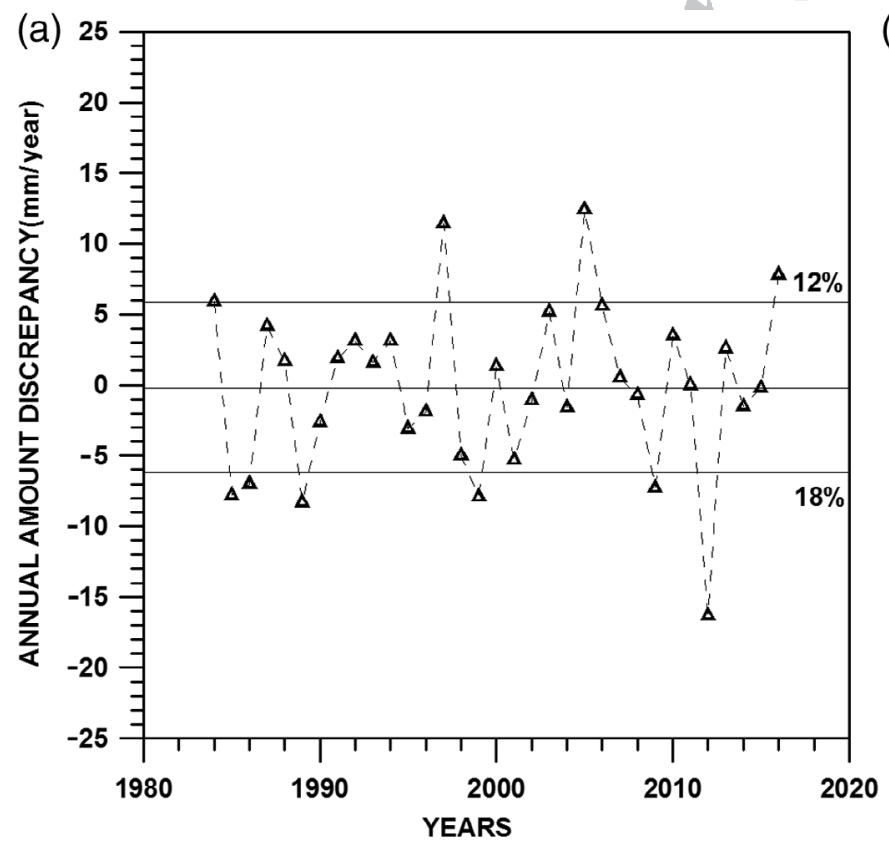

(b)

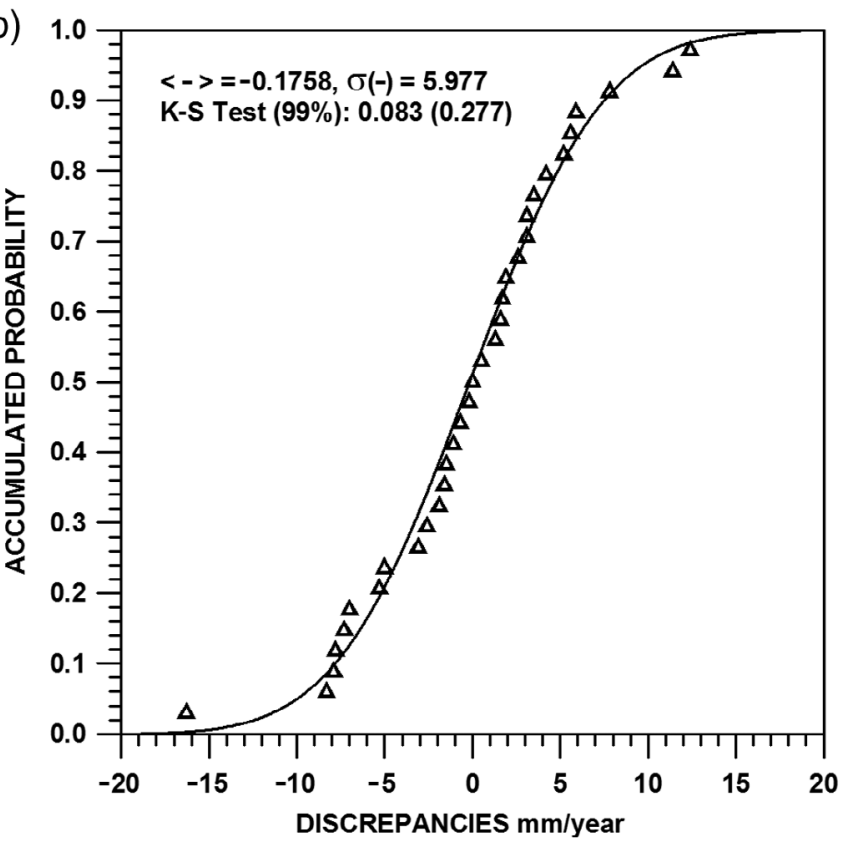

FI G URE 11 (a) Evolution of the annual amounts deduced from monthly records and predicted monthly values for the Fabra

Observatory. (b) Statistical distribution, based on a normal distribution, of annual discrepancies between real and predicted amounts 
1 predicted annual amounts for the Fabra observatory, as 2 well as the statistical distribution of annual discrepancies 3 (Figure 11b), assuming the predicted annual amounts as 4 the sum of the corresponding predicted monthly values. 5 It is worth mentioning that the extreme discrepancies at 6 annual scale are within a narrow range of approximately $7 \quad\left(-20,+20 \mathrm{~mm} \cdot\right.$ year $\left.^{-1}\right)$, very small in comparison to the 8 average annual amount $\left(623.0 \mathrm{~mm} \cdot \mathrm{year}^{-1}\right)$. Only $12 \%$ of 9 cases exceed positive discrepancies of $5.8 \mathrm{~mm} \cdot$ year $^{-1}$ 10 while $18 \%$ of cases show negative discrepancies below $11-6.2 \mathrm{~mm} \cdot$ year $^{-1}$. According to these results, the monthly 12 scale ARIMA autoregressive process could also be used to 13 predict rainfall amounts on an annual scale. It is also 14 worth mentioning that the empiric distribution of annual 15 discrepancies can also be well-fitted to a normal distribu16 tion, confirmed by the certainty given by the 17 Kolmogorov-Smirnov test.

19 ing: the degree of randomness or persistence of the monthly series, the decrease in the correlation between monthly data with increasing lag times among them, the number of necessary nonlinear equations to quantify monthly amounts and the complexity of the multifractal structure of monthly rainfall. A slightly lesser spatial complexity is detected for the MAD parameter, with all its values less than the standard deviations of the corresponding monthly amount series that have been analysed. Due to this fact, the degree of certainty of the predicted monthly amounts is acceptable. As a counterpart, high values of the NPMAX parameter are necessary, which then reduce the number of months to be tested and affect an extreme exactitude on the MAD parameter. Nevertheless, taking into account the outstanding differences between MAD (ranging from 1.4 to $20.6 \mathrm{~mm} \cdot \mathrm{month}^{-1}$ ) and the standard deviation of monthly amounts (ranging from 31.8 to $80.3 \mathrm{~mm} \cdot \mathrm{month}^{-1}$ ), all the analysed series are expected to be accurately predicted by means of the ARIMA algorithm. Given that the MAD parameter quantifies the discrepancy between real and predicted monthly amounts, its spatial distribution should be closely related to the Lyapunov exponents, which quantify the degree of predictive instability of a fractal structure, and also related to the mentioned multifractal Complexity index.

A final relevant question is the applicability of the ARIMA algorithm to the prediction of drought episodes, consisting of consecutive months with rainfall amounts below a threshold level. From this perspective, predicting consecutive monthly amounts is necessary to decide if the next monthly amount would be lower than the chosen threshold level, which would then lengthen a drought episode. The two examples tested for the Ebre and Fabra Observatories would be a good example of predicting the continuity and end of a drought episode. The success of this strategy, based on the results of the ARIMA algorithm, should be assumed from several points of view. First, there are low probabilities of excessive discrepancies between real and predicted amounts; second, only a few months with amounts very close to the chosen threshold $\left(30.0 \mathrm{~mm} \cdot \mathrm{month}^{-1}\right)$ change their contribution to the continuity of a drought episode when predicted amounts slightly exceed the threshold level; third, the discrepancies on an annual scale represent a low percentage with respect to the real amount, which reinforces the reliability of the ARIMA process results. This possible control of drought length and accumulated rainfall deficit on a monthly scale could be very useful for Mediterranean areas like Catalonia, where drought episodes, some of them severe, are quite frequent and detection on a monthly scale is very important.

Some consequences derived from the drought episodes, usually common to Mediterranean countries, are 
1 forest fires, usually in the summer season, sometimes 2 devastating a notable number of hectares. Other exam3 ples are bad crops due to minimum rain amounts and 4 heat waves. Drought episodes in Spring and Autumn are 5 very important for the pluviometric regime in Catalonia 6 given that these are the two seasons with the usual 7 highest contribution to annual amounts. Additionally, a 8 winter low amount of snow in the Pyrenees could notably 9 reduce the reservoir levels in spring, strongly affecting 10 the water supply if this fact is accompanied by a drought 11 episode in the same season.

In short, the research of this paper could be the starting point to mitigate the effects of drought episodes in Catalonia by taking into account that, except for a few emplacements, the discrepancies between real and predicted monthly amounts are sufficiently small. In this way, the relevant factor could not be an exact detection of the starting and ending month of a drought episode, but an estimation of the evolution for the next monthly amount and how to mitigate the effects of a drought episode.

\section{ACKNOWLEDGEMENTS}

The authors thank the Servei Meteorològic de Catalunya (SMC) for providing rainfall data used in this study. The authors also thank the editor and the anonymous reviewers for their valuable comments and suggestions to improve the manuscript.

\section{CONFLICT OF INTEREST}

The authors declare no potential conflict of interest.

\section{ORCID}

Xavier Lana (1) https://orcid.org/0000-0002-3298-9234

Raül Rodríguez-Solà (1) https://orcid.org/0000-0002-9623894X

M. Carmen Casas-Castillo (1) https://orcid.org/0000-00027507-6195

\section{REFERENCES}

Alpert, P., Ben-Gai, T., Baharad, A., Benjamini, Y., Yekutieli, D., Colacino, M., Diodato, L., Ramis, C., Homar, V., Romero, R., Michaelides, S. and Manes, A. (2002) The paradoxical increase of Mediterranean extreme daily rainfall in spite of decrease in total values. Geophysical Research Letters, 29(11) 31-1-31-4. https://doi.org/10.1029/2001GL013554.

Anagnostopoulou, C., Maheras, P., Karacostas, T. and Vafiadis, M. (2003) Spatial and temporal analysis of dry spells in Greece. Theoretical and Applied Climatology, 74, 77-91. https://doi.org/ 10.1007/s00704-002-0713-5.

Barry, R.G. and Chorley, R.J. (2003) Atmosphere, Weather and Climate, 8th edition. London, UK: Rouledge.

Box, G.E.P. and Jenkins, G.M. (1976) Time Series Analysis: Forecasting and Control. CA: Holden-Day 575 pp.
Casas, M.C., Herrero, M., Ninyerola, M., Pons, X., Rodríguez, R., Rius, A. and Redaño, A. (2007) Analysis and objective mapping of extreme daily rainfall in Catalonia. International Journal of Climatology, 27(3), 399-409. https://doi.org/10.1002/joc.1402.

Casas-Castillo, M.C., Llabrés-Brustenga, A., Rius, A., RodríguezSolà, R. and Navarro, X. (2018) A single scaling parameter as a first approximation to describe the rainfall pattern of a place: application on Catalonia. Acta Geophysica, 66(3), 415-424. https://doi.org/10.1007/s11600-018-0122-5.

Clavero, P., Martín-Vide, J. and Raso, J. (1996) Atlas climàtic de Catalunya: termopluviometria. Departament de Medi Ambient, Generalitat de Catalunya $42 \mathrm{pp}$.

Diks, C. (1999) Nonlinear time series analysis. Methods and applications. In: Tong, H. (Ed.) Nonlinear Time Series and Chaos, Vol. 4. London: World Scientific, p. 209.

Diodato, N. and Bellocchi, G. (2008) Drought stress patterns in Italy using agroclimatic indicators. Climatic Research, 36, 53-63. https://doi.org/10.3354/cr00726.

Dodge, Y. (2008) The Kolmogorov-Smirnov test. In: The Concise Encyclopedia of Statistics. New York, NY: Springer.

Hanel, M., Rakovec, O., Markonis, Y., Máca, P., Samaniego, L., Kyselý, J. and Kumar, R. (2018) Revisiting the recent European droughts from a long-term perspective. Scientific Reports, 8, 9499. www.nature.com/scientificreports. https://doi.org/10. 1038/s41598-018-27464-4.

Hosking, J.R.M. and Wallis, J.R. (1997) Regional Frequency Analysis. Cambridge UK: Cambridge University Press 224 pp.

Kantelhardt, J.W., Zschiegner, S.A., Koscielny-Bunde, A., Havlin, S., Bunde, A. and Stanley, H.E. (2002) Multifractal detrended fluctuation analysis of nonstationary time series. Physica A: Statistical Mechanics and its Applications, 316(1-4), 87-114. https://doi.org/10.1016/S0378-4371(02)01383-3.

Kutiel, H. (1985) The multimodality of the rainfall course in Israel, as reflected by the distribution of dry spells. Archives for Meteorology, Geophysics, and Bioclimatology, Series B, B36, 15-27. https://doi.org/10.1007/BF02269454.

Kutiel, H. and Maheras, P. (1992) Variations interannuelles des séquences sèches et de situations synoptiques en Méditerranée Orientale. Publications de l'Association Internationale de Climatologie, 5, 249-253.

Labuhn, I., Daux, V., Girardclos, O., Stievenard, M., Pierre, M. and Masson-Delmotte, V. (2016) French summer droughts since 1326 $\mathrm{CE}$ : a reconstruction based on tree ring cellulose $\delta^{18} \mathrm{O}$. Climate of the Past, 12, 1101-1117. https://doi.org/10.5194/cp-12-1101-2016.

Lana, X. and Burgueño, A. (1998a) Probabilities of repeated long dry episodes based on the Poisson distributions. An example for Catalonia (NE Spain). Theoretical and Applied Climatology, 60, 111-120. https://doi.org/10.1007/s007040050037.

Lana, X. and Burgueño, A. (1998b) Spatial and temporal characterization of annual extreme droughts in Catalonia (Northeast Spain). International Journal of Climatology, 18, 93-110 https:// doi.org/10.1002/(SICI)1097-0088(199801)18:1<93::AIDJOC219>3.0.CO;2-T.

Lana, X., Burgueño, A., Martínez, M.D. and Serra, C. (2006b) Statistical distributions and sample strategies for the analysis of extreme dry spells in Catalonia (NE Spain). Jounal of Hydrology, 324, 94-114. https://doi.org/10.1016/j.jhydrol.2005.09.013.

Lana, X., Burgueño, A., Martínez, M.D. and Serra, C. (2009) A review on dry spells statistics in Catalonia (NE Spain). In: 
Sánchez, J.M. (Ed.) Chapter 6, 191-218Droughts: Causes, Effects and Predictions. New York: Nova Science. ISBN: 978-1-60456-285-9.

Lana, X., Burgueño, A., Serra, C. and Martínez, M.D. (2017) Monthly rain amounts at Fabra observatory (Barcelona, NE Spain): fractal structure, autoregressive processes and correlation with monthly Western Mediterranean oscillation index. International Journal of Climatology, 37, 1557-1577. https://doi. org/10.1002/joc.4797.

Lana, X., Martínez, M.D., Burgueño, A. and Serra, C. (2008b) Return period maps of dry spells for Catalonia (NE Spain) based on the Weibull distribution. Hydrological Sciences Journal, 51, 48-64. https://doi.org/10.1623/hysj.53.1.48.

Lana, X., Martínez, M.D., Burgueño, A., Serra, C., Martín-Vide, J. and Gómez, L. (2006a) Distribution of long dry spells in the Iberian Peninsula, years 1951-1990. International Journal of Climatology, 26(1992), 2021-2021. https://doi.org/10.1002/joc. 1354.

Lana, X., Martínez, M.D., Burgueño, A., Serra, C., Martín-Vide, J. and Gómez, L. (2008a) Spatial and temporal patterns of dry spell lengths in the Iberian Peninsula for the second half of the $20^{\text {th }}$ century. Theoretical and Applied Climatology, 91, 99-116. https://doi.org/10.1007/s00704-007-0300-x.

Lana, X., Rodríguez-Solà, R., Martínez, M.D., Casas-Castillo, M.C., Serra, C. and Kirchner, R. (2020); https://doi.org/10.1063/5. 0010342) Multifractal structure of the monthly rainfall regime in Catalonia (NE Sain): evaluation of the non-linear structural complexity. Chaos: Interdisciplinary Journal of Nonlinear Science, 30073117.

Lana, X., Serra, C. and Burgueño, A. (2001) Patterns of monthly rainfall shortage and excess in terms of the standardized precipitation index for Catalonia (NE Spain). International Journal of Climatology, 21, 1669-1691. https://doi.org/10.1002/joc.697.

Llabrés-Brustenga, A., Rius, A., Rodríguez-Solà, R. and CasasCastillo, M.C. (2020) Influence of regional and seasonal rainfall patterns on the ratio between fixed and unrestricted measured intervals of rainfall amounts. Theoretical and Applied Climatology, 140, 389-399. https://doi.org/10.1007/s00704-020-03091-w.

Llabrés-Brustenga, A., Rius, A., Rodríguez-Solà, R., CasasCastillo, M.C. and Redaño, A. (2019) Quality control process of the daily rainfall series available in Catalonia from 1855 to the present. Theoretical and Applied Climatology, 137(3-4), 2715-2729. https://doi.org/10.1007/s00704-019-02772-5.

Llasat, M.C., Llasat-Botija, M., Barnolas, M., López, L. and AltavaOrtiz, V. (2009) An analysis of the evolution of hydrometeorological extremes in newspapers: the case of Catalonia, 1982-2006. Natural Hazards and Earth System Sciences, 9(4), 1201-1212. https://doi.org/10.5194/nhess-9-1201-2009.

Martínez, M.D., Lana, X. and Burgueño, A. (2010) Long-term rainfall monthly shortage in Spain: spatial patterns, statistical models and time trends. International Journal of Climatology, 30, 1668-1688. https://doi.org/10.1002/joc.2017.

Martínez, M.D., Lana, X., Burgueño, A. and Serra, C. (2007) Spatial and temporal daily rainfall regime in Catalonia (NE Spain) derived from four precipitation indices, years 1950-2000.
International Journal of Climatology, 27, 123-138. https://doi. org/10.1002/joc.1369.

Mc Night, T.L. and Hess, D. (2000) Climate Zone and Types. Physical Geography. A Landscape Appreciation. Upper Saddle River, NJ: Prentice Hall pp. 200.

Nastos, P.T. and Zerefos, C.S. (2009) Spatial and temporal variability of consecutive dry and wet days in Greece. Atmospheric Research, 94, 616-628. https://doi.org/10.1016/j.atmosres.2009. 03.009 .

Press, W.H., Teukolsky, S.A., Vetterling, W.T. and Flannery, B.P. (1992) Numerical Recipes in FORTRAN, 2nd edition. Cambridge, UK: Cambridge University Press.

Press, W.H., Teukolsky, S.A., Vetterling, W.T. and Flannery, B.P. (2007) Interpolation by Kriging: Section 3.7.4. Numerical Recipes: The Art of Scientific Computing, 3rd edition. New York: Cambridge University Press. isbn:978-0-521-88068-8.

Sergent, A.S., Rozenberg, P. and Bréda, N. (2014) Douglas-fir is vulnerable to exceptional and recurrent drought episodes and recovers less well on less fertile sites. Annals of Forest science, springer Verlag/EDP. Sciences, 71, 697-708. https://doi.org/10. 1007/s13595-012-0220-5.

Serra, C., Burgueño, A., Martínez, M.D. and Lana, X. (2006) Trends of dry spells across Catalonia (NE Spain) for the second half of the $20^{\text {th }}$ century. Theoretical and Applied Climatology, 85, 165-183. https://doi.org/10.1007/s00704-005-0184-6.

Shimizu, Y., Thurner, S. and Ehrenberger, K. (2002) Multifractal spectra as a measure of complexity human posture. Fractals, 10, 104-116. https://doi.org/10.1142/S0218348X02001130.

Stein, M.L. (1999) Statistical Interpolation of Spatial Data: Some Theory for Kriging. New York: Springer.

Stephenson, D.B., Pavan, V. and Bojariu, R. (2000) Is the North Atlantic oscillation a random walk? International Journal of Climatology, 20, 1-18 https://doi.org/10.1002/(SICI)1097-0088 (200001)20:1<1::AID-JOC456>3.0.CO;2-P.

Van Hateren, T.C., Sutanto, S.J. and Van Lanen, H.A. (2019) Evaluating skill and robustness of seasonal meteorological and hydrological drought forecasts at the catchment scale-case Catalonia (Spain). Environment International, 133, 105206. https:// doi.org/10.1016/j.envint.2019.105206.

Vicente-Serrano, S.M. (2006) Spatial and temporal analysis of droughts in the Iberian Peninsula (1910-2000). Hydrological Sciences Journal, 51, 83-97. https://doi.org/10.1623/hysj.51. 1.83.

How to cite this article: Lana $\mathrm{X}$, RodríguezSolà R, Martínez MD, Casas-Castillo MC, Serra C, Kirchner R. Autoregressive process of monthly rainfall amounts in Catalonia (NE Spain) and improvements on predictability of length and intensity of drought episodes. Int J Climatol. 2020; 1-16. https://doi.org/10.1002/joc.6915 
The contents of this page will be used as part of the graphical abstract of html only.

It will not be published as part of main.

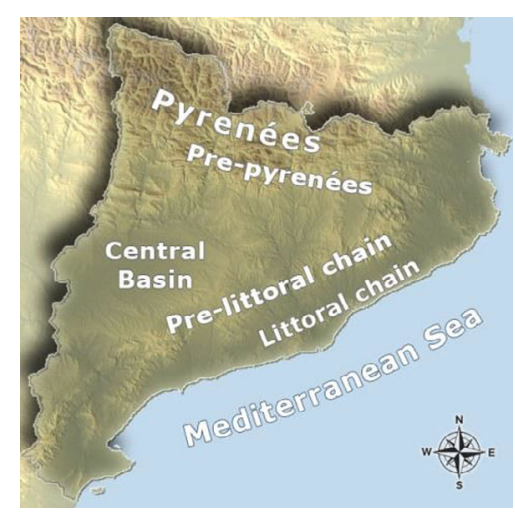

Daily rainfall data from almost a hundred meteorological stations managed by the public administrative organism Meteorological Service of Catalonia, SMC, from 1960 to 2000, have allowed a detailed analysis of the results offered by the ARIMA algorithm on a monthly scale. These results allow the forecasting of the duration and intensity of drought episodes, quite common in Catalonia, which affect success of harvests, water supply, human health or increased risk of forest fires.

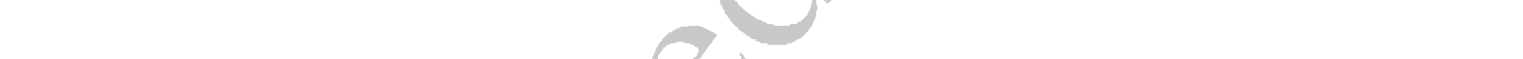

